\title{
Radioactivity of long-lived gamma emitters in egg
}

\author{
Hamid Ramazanian*, Tareq Alrefae \\ Dept. of Physics, Faculty of Science, Kuwait University, \\ Shadadiyah, Kuwait. \\ *Corresponding author: hamid.ramazanian@ku.edu.kw
}

\begin{abstract}
Radioactivity in the egg was investigated. The targeted radionuclides were the long-lived gamma emitters ${ }^{228} \mathrm{Ra},{ }^{226} \mathrm{Ra}$, and ${ }^{40} \mathrm{~K}$. Measurements were carried out using a high purity germanium detector. Based on an annual intake of $29 \mathrm{~kg}$, the calculated annual effective dose due to egg consumption was $79 \mu \mathrm{Sv} \mathrm{yr}{ }^{-1}$, which forms $1 / 4$ of the $290 \mu \mathrm{Sv} \mathrm{yr}^{-1}$ world average ingestion exposure from natural sources. Hence, no radiological hazards exist from egg consumption due to the presence of the investigated radionuclides.
\end{abstract}

Keywords: Egg; foodstuff; gamma spectrometry; Kuwait; NORM.

\section{Introduction}

Radiation in the environment is due to anthropogenic as well as natural sources. Anthropogenic sources are products of man-made radioactive processes in medical, military, and industrial applications. Examples of anthropogenic sources are Cs-137 and I-131. Releases of unintentional discharges can regulate discharges of anthropogenic radioactivity to the environment. An example of a regulated release is the incineration of an industrial radioactive source (Ortiz, 1999). Another example of a regulated release is when military nuclear tests are conducted; Examples of such armed training are the nuclear tests that took place last century in the South Pacific and the deserts of Nevada. Conversely, examples of unintentional releases of anthropogenic radioactivity are the nuclear power plant accidents in Chernobyl in 1986 (Beresford, 2016) and Fukushima in 2011 (Ishikawa, 2017).

Natural radioactivity, on the other hand, is caused by natural sources. Some examples of natural radionuclides are Thorium $\left({ }^{232} \mathrm{Th}\right)$, Uranium $\left({ }^{238} \mathrm{U}\right)$, and potassium ${ }^{40} \mathrm{~K}$. These natural substances, also known as naturally occurring radioactive material (NORM), are present in the environment in different concentrations. In addition to this ubiquitous presence, NORM is exceptionally longlived, with half-lives in $10^{9}$ years.

Regardless of being anthropogenic or natural, radionuclides enter the human body through four main pathways. One pathway is inhalation, which occurs when airborne radionuclides enter the human body through the nose or the mouth to the respiratory system. Another pathway is absorption, which occurs when radionuclides enter the human body through the skin to the bloodstream. Another pathway is an injection, which occurs when the radionuclide is intravenously injected inside the body. And another pathway is ingestion, which arises when radionuclides enter 
through the mouth to the digestive system. Irrespective of the pathway, both allowed entrance and unwanted intrusion of radionuclides into the human body cause internal exposure, leading to significant health effects (Fry, 1990).

Among the most important pathway is ingestion. This importance emanates from the daily act of eating. Moreover, this importance is enhanced by knowing that food contains NORM. In other words, the internal exposure of humans to radioactivity is primarily caused by food consumption. This recognized fact aroused and concerned researchers and health professionals worldwide, which led to numerous studies about the radioactivity of food. One primary goal of such studies is to establish a baseline of internal radioactivity exposure to humans from radionuclide ingestion as a by-product of food consumption (Osvath, 2016), (Faahnhof, 2003).

A literature search shows numerous studies on various food types (Shanthi, 2009), (Olomo, 1990). Interestingly, more food types are yet to be studied. One food item that is worthy of investigation is poultry eggs. Owing to their availability and palatability, eggs are popularly consumed worldwide. Hence this work aimed to investigate the NORM in eggs.

\section{Materials and methods}

Fresh egg samples were collected from conventional and farm markets across 8 countries. For an adequate representation, 25 different samples were gathered, as shown in Table 1. Before measurement, each sample underwent proper lab preparation following standard procedures (IAEA, 1989). The preparation involved cracking each egg individually before allowing its contents, namely white and Yolk, to fall into a shallow container. Then, the white and Yolk were thoroughly mixed before placing the container inside a freeze drier (except for samples $16 \& 17$, since they are the white and Yolk (separately) of one of the samples, respectively). The horizontal geometry of the container was deliberately chosen to enhance freeze-drying. After the moisture content was stripped away, the sample was blended to make a powder before being placed in cylindrical containers $6 \mathrm{~cm}$ in height and $6 \mathrm{~cm}$ in diameter. After applying a tight seal to every container, all samples were left for one month to allow for secular equilibrium.

Table 1. The origin of samples in this study

\begin{tabular}{|cl|cl|ll|}
\hline ID & Country of Origin & ID & Country of Origin & ID & Country of Origin \\
\hline 1 & Bangladesh & 10 & Kuwait & 18 & Kuwait \\
2 & Jordon & 11 & Kuwait & 19 & Lebanon \\
3 & Kuwait & 12 & Kuwait & 20 & Lebanon \\
4 & Kuwait & 13 & Kuwait & 21 & Saudi \\
5 & Kuwait & 14 & Kuwait & 22 & Turkey \\
6 & Kuwait & 15 & Kuwait & 23 & Turkey \\
7 & Kuwait & 16 & Kuwait & 24 & UAE \\
8 & Kuwait & 17 & Kuwait & 25 & USA \\
9 & Kuwait & & & & \\
\hline
\end{tabular}


Counting was carried out with high purity germanium (HPGe) detector. This p-type, low background instrument had a resolution of energy of $1.7 \mathrm{keV} \mathrm{FWHM}$ at the $1.33 \mathrm{MeV}$ photopeak of Co-60. The counting system was of $80 \%$ relative efficiency and was equipped with a cylindrical detector of $8.8 \mathrm{~cm}$ and $7.4 \mathrm{~cm}$ in diameter. Energy calibration was done using a set of point sources of various energy photopeaks that covers the required spectrum. These point sources were Am241, Cs-137, and Co-60. Moreover, the efficiency calibration was performed using reference materials of the same geometry and density of the egg samples. Efficiency calculations were performed using the formula (Knoll, 2000)

$\epsilon=N / A P \gamma t m$

In this equation, $N$ is the net counts of the relevant photopeak, $A$ is the concentration of the activity, $P \gamma$ is the probability of emission per disintegration for the relevant photopeak, and $m$ is the mass of the sample, and $t$ is the counting time.

Each sample was counted for one whole day. This lengthy counting time was necessary to reduce statistical errors. An empty container identical to the sample-holding containers was measured under the same conditions to obtain background counts. To analyze the spectrum, commercial software was used, namely, Gamma Vision, where the targeted peaks were $583 \mathrm{keV}$, $295 \mathrm{keV}$, and $1461 \mathrm{keV}$ corresponding to gamma emission peaks of ${ }^{228} \mathrm{Ra},{ }^{226} \mathrm{Ra}$, and ${ }^{40} \mathrm{~K}$, respectively. Ultimately, the activity concentration was computed for all samples using the following equation (IAEA, 1989)

$A=N / \epsilon P \gamma t m$

where $A$ is the activity concentration (in $\mathrm{Bk} / \mathrm{kg}$ ). For reliable readings, the minimum detectable activity (MDA) was calculated using the formula (Currie, 1968)

$M D A=2.71+4.66 S b / \epsilon P \gamma t m$

where $S b$ is the standard error in the net background count for the photopeak. The $M D A$ values for the counting system were calculated to be $1.3,1.9$, and $17.5 \mathrm{~Bq} \mathrm{~kg}^{-1}$ for ${ }^{228} \mathrm{Ra},{ }^{226} \mathrm{Ra}$, and ${ }^{40} \mathrm{~K}$, respectively.

\section{Results}

Table 2 presents the activity concentrations for ${ }^{228} \mathrm{Ra},{ }^{226} \mathrm{Ra}$, and ${ }^{40} \mathrm{~K}$ in egg samples. ${ }^{40} \mathrm{~K}$ was detected in all samples with a maximum value of $378.4 \pm 8.99 \mathrm{~Bq} \mathrm{~kg}^{-1}$ (sample 16-Kuwait), a minimum value of $76.3 \pm 5.97 \mathrm{~Bq} \mathrm{~kg}^{-1}$ (sample 17-Kuwait), and an all-brand, all countries average of $( \pm \mathrm{SD}) 193.9 \pm 46.6 \mathrm{~Bq} \mathrm{~kg}^{-1}$. (Figure 1$)$.

Above the MDA, activity concentrations for ${ }^{226} \mathrm{Ra}$ were found in 6 samples only. The maximum value was $3.6 \pm 0.70 \mathrm{~Bq} \mathrm{~kg}^{-1}$ (sample 10-Kuwait) and $3.6 \pm 0.64$ (sample 19-Lebanon), the minimum value was $2.1 \pm 0.63 \mathrm{~Bq} \mathrm{~kg}^{-1}$ (sample 11-Kuwait). The average activity concentration for all detected samples was $3.1 \pm 0.60 \mathrm{~Bq} \mathrm{~kg}^{-1}( \pm \mathrm{SD})$. (AVG $\left.\pm \mathrm{SD}\right)$. (Figure 2) 
Table 2. Activity concentrations $\left(\mathrm{Bq} \mathrm{kg}^{-1}\right)$ of ${ }^{228} \mathrm{R},{ }^{226} \mathrm{R}$, and ${ }^{40} \mathrm{~K}$ for samples in this study

\begin{tabular}{|c|c|c|c|}
\hline ID & ${ }^{228} R$ & ${ }^{226} R$ & ${ }^{40} \mathbf{K}$ \\
\hline 1 & $1.3 \pm 0.47$ & BDL & $149.1 \pm 7.10$ \\
\hline 2 & ND & $3.4 \pm 0.40$ & $189.6 \pm 6.83$ \\
\hline 3 & $2.1 \pm 0.46$ & ND & $178.5 \pm 6.99$ \\
\hline 4 & BDL & BDL & $175.6 \pm 7.27$ \\
\hline 5 & BDL & BDL & $171.7 \pm 7.00$ \\
\hline 6 & $1.5 \pm 0.54$ & BDL & $205.1 \pm 8.37$ \\
\hline 7 & $1.4 \pm 0.48$ & ND & $183.9 \pm 7.44$ \\
\hline 8 & $1.7 \pm 0.43$ & ND & $204.6 \pm 6.78$ \\
\hline 9 & $\mathrm{BDL}$ & ND & $169.7 \pm 7.23$ \\
\hline 10 & BDL & $3.6 \pm 0.70$ & $205.3 \pm 7.45$ \\
\hline 11 & BDL & $2.1 \pm 0.63$ & $211.7 \pm 7.08$ \\
\hline 12 & $1.7 \pm 0.46$ & $\mathrm{BDL}$ & $188.9 \pm 7.11$ \\
\hline 13 & $\mathrm{BDL}$ & ND & $194.2 \pm 7.14$ \\
\hline 14 & $2.3 \pm 0.47$ & BDL & $179.1 \pm 7.05$ \\
\hline 15 & $2.1 \pm 0.52$ & $2.4 \pm 0.73$ & $215.1 \pm 8.05$ \\
\hline 16 & $2.9 \pm 0.54$ & ND & $378.4 \pm 8.99$ \\
\hline 17 & $1.7 \pm 0.43$ & ND & $76.3 \pm 5.97$ \\
\hline 18 & $1.7 \pm 0.46$ & ND & $177.2 \pm 7.04$ \\
\hline 19 & $2.2 \pm 0.44$ & $3.6 \pm 0.64$ & $212.7 \pm 6.91$ \\
\hline 20 & $2.7 \pm 0.45$ & ND & $207.8 \pm 6.89$ \\
\hline 21 & $1.3 \pm 0.43$ & BDL & $194.3 \pm 6.87$ \\
\hline 22 & $1.5 \pm 0.60$ & ND & $178.1 \pm 9.12$ \\
\hline 23 & $3.0 \pm 0.44$ & ND & $202.7 \pm 6.57$ \\
\hline 24 & $2.0 \pm 0.45$ & $3.3 \pm 0.65$ & $194.2 \pm 6.97$ \\
\hline 25 & $2.6 \pm 0.61$ & ND & $204.2 \pm 9.09$ \\
\hline
\end{tabular}

Activity concentrations above the MDA for ${ }^{228} \mathrm{Ra}$ were found in 18 samples only. The maximum value was $3.0 \pm 0.44 \mathrm{~Bq} \mathrm{~kg}^{-1}$ (sample 22-Turkey), and the minimum value was $1.3 \pm 0.47 \mathrm{~Bq} \mathrm{~kg}^{-1}$ (sample 1-Bangladesh), and $1.3 \pm 0.43 \mathrm{~Bq} \mathrm{~kg}^{-1}$ (sample 21-Saudi). The average activity concentrations for all detected samples were $2.0 \pm 0.50 \mathrm{~Bq} \mathrm{~kg}^{-1}$. (Figure 3).

It is noteworthy that the maximum and minimum values of the activity concentrations of ${ }^{40} \mathrm{~K}$ given above are for the white and Yolk (samples $16 \& 17-$ Kuwait), respectively (the activity concentration of ${ }^{40} \mathrm{~K}$ for white (378.4) is 5 times that for yolk (76.3). Furthermore, the activity concentrations of ${ }^{228} \mathrm{Ra}$, for the white and Yolk for the same brand are close to the maximum and minimum values given above. These differences could be explained as natural because of the difference in the compositions between white eggs and Yolk. 


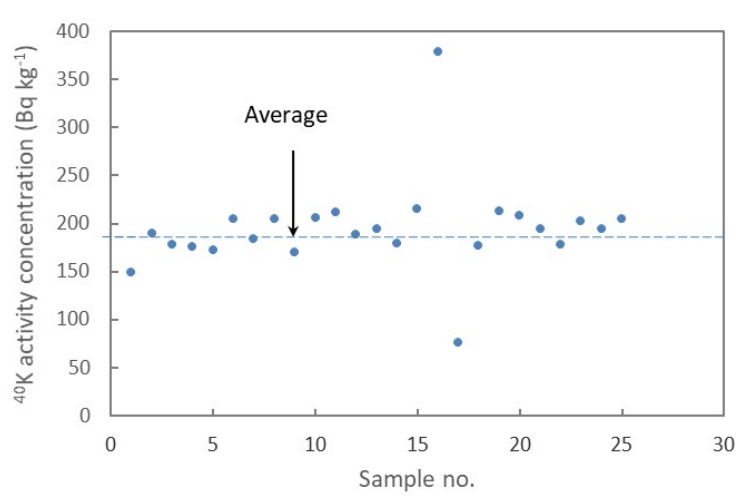

Fig. 1. Activity concentration of ${ }^{40} \mathrm{~K}$

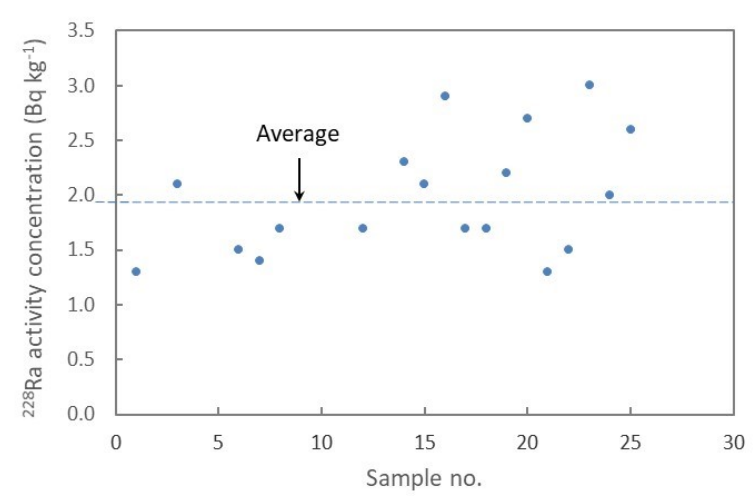

Fig. 2. Activity concentration of ${ }^{226} \mathrm{Ra}$

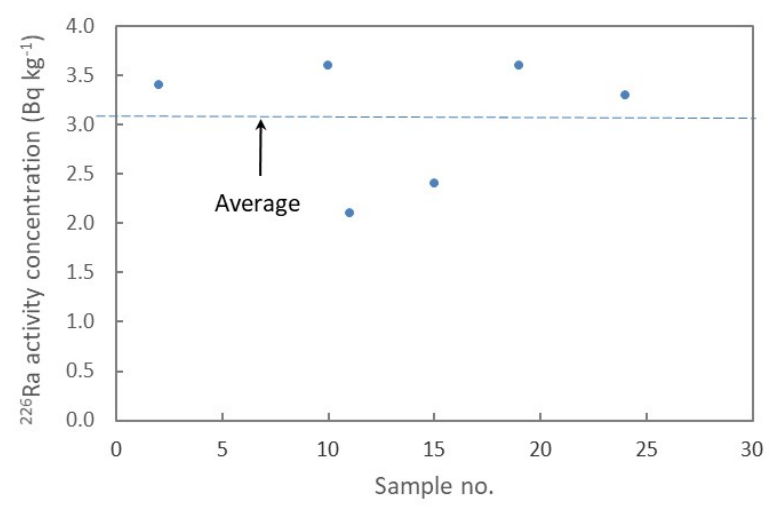

Fig. 3. Activity concentration of ${ }^{228} \mathrm{Ra}$

\section{Discussion}

Based on studies of the radioactivity in several foodstuffs reported in the literature (Alrefae, 2012; Alrefae, 2013; Alrefae, 2013; Alrefae, 2014; Alrefae, 2015), the detection of natural radionuclides in eggs was expected. Also, and in agreement with those studies, ${ }^{40} \mathrm{~K}$ is detected in all samples. Furthermore, the absence of ${ }^{228} \mathrm{Ra}$, and ${ }^{226} \mathrm{Ra}$ in some samples (in agreement with studies reported in the literature) (Hosseini et al., 2006; Yu and Mao, 1999) was natural and could be explained by the fact that system MDA and the background levels could hide minor photo-peaks (Knoll, 2000).

Comparing the present study results to studies reported in the literature, Table 3 shows the activity concentration of the targeted radionuclides in different food items. For example, the activity concentration value of ${ }^{40} \mathrm{~K}$ in the egg overlaps with its counterpart in cereal, milk, and palm dates. In contrast, it is one order of magnitude higher than seafood. On the other hand, the activity concentration of ${ }^{228} \mathrm{Ra}$ in eggs overlaps with its counterpart in cereal and exceeds it. Comparing median values, the activity concentration of ${ }^{228} \mathrm{Ra}$ in the egg is three times higher than its counterpart in milk and palm dates. As for the activity concentration of ${ }^{226} \mathrm{Ra}$, a median value comparison shows more than twice in the egg than in the other food items. 
Table 3. Activity concentrations $\left(\mathrm{Bq} \mathrm{kg}^{-1}\right)$ of ${ }^{228} \mathrm{R},{ }^{226} \mathrm{R}$, and ${ }^{40} \mathrm{~K}$ for samples in this study compared to values determined for other foodstuffs

\begin{tabular}{|l|c|c|c|c|}
\hline Foodstuff & ${ }^{228} \mathbf{R}$ & ${ }^{226} \mathbf{R}$ & ${ }^{\mathbf{4 0}} \mathbf{K}$ & Reference \\
\hline Egg & $1.3-3.0$ & $2.1-3.6$ & $76-378$ & (Present study) \\
\hline Cereal & $0.29-1.52$ & $0.32-0.75$ & $14-300$ & (Alrefae, 2013) \\
\hline Seafood & & $0.4-2.0$ & $5-42$ & (Alrefae, 2014) \\
\hline Milk & $0.29-0.69$ & $0.32-0.98$ & $162-695$ & (Alrefae, 2012) \\
\hline Palm dates & $0.23-1.1$ & $0.47-1.9$ & $236-417$ & (Alrefae, 2015) \\
\hline
\end{tabular}

On the other side, the present study revealed a significant difference in the activity concentrations of ${ }^{40} \mathrm{~K}$ and ${ }^{228} \mathrm{Ra}$ in white eggs compared to Yolk for one of the egg samples, where the activity concentrations of ${ }^{40} \mathrm{~K}$ in the white egg were 5 times that for Yolk for that sample, and the activity concentrations of ${ }^{228} \mathrm{Ra}$ in the white egg was double that for Yolk for the same sample. This could be explained as the difference in the composition between white egg and Yolk and suggests further investigations of the radioactivity of the targeted radionuclides to be carried out on white egg and Yolk separately.

The annual adequate dose $D\left(\mathrm{~Sv} \mathrm{yr}^{-1}\right)$ from consumption of egg was calculated using the formula (Unscear, 2000)

$D=A E I$

In this equation, $A$ is the concentration of the activity $\left(\mathrm{Bq} \mathrm{kg}^{-1}\right) . E$ is the factor of dose conversion, which was taken following the reports of the International Commission on Radiological Protection classifications (ICRP, 1996), like 303, 280, and $6.4 \mathrm{nSv} \mathrm{Bq}^{-1}$ for ${ }^{228} \mathrm{Ra}^{226} \mathrm{Ra}$, and ${ }^{40} \mathrm{~K}$, respectively, and $I$ is the annual intake of egg $(\mathrm{kg})$. The value of $I$ is taken to be $29 \mathrm{~kg} \mathrm{yr}^{-1}$ based on the Statista research department (Statista Research \& Analysis is the analytical unit of one of the world's largest statistics portals that equip businesses with a variety of individually tailored R\&A services).

The annual effective doses determined are 17.5 $\mu \mathrm{Sv}, 25.2 \mu \mathrm{Sv}$, and $36.3 \mu \mathrm{Sv}$, corresponding to ${ }^{228} \mathrm{Ra},{ }^{226} \mathrm{Ra}$, and ${ }^{40} \mathrm{~K}$ ingestion, respectively. Therefore, the adequate yearly amount from the three targeted radionuclides due to egg ingestion is $79 \mu \mathrm{Sv}$, which is $1 / 4$ of $290 \mu \mathrm{Sv} \mathrm{yr}{ }^{-1}$, the reported world average exposure by ingestion NORM (Unscear, 2000). Hence, no radiological hazards exist from egg consumption due to the presence of the investigated radionuclides.

Table 4 presents the annual effective doses $\left(\mu \mathrm{Sv} \mathrm{yr}^{-1}\right)$ of ${ }^{228} \mathrm{R},{ }^{226} \mathrm{R}$, and ${ }^{40} \mathrm{~K}$ for samples in this study, compared to values determined for the other listed foodstuff. The total annual effective dose 
in the present study is significantly lower than that for cereal, whereas it is higher than those for other listed food items. This relation is valid for ${ }^{226} \mathrm{R}$ as well. Likewise, the annual effective dose for ${ }^{40} \mathrm{~K}$ is lower than its counterparts in cereal \& milk, but it is higher than values for other listed food items. Finally, the annual effective dose for ${ }^{228} \mathrm{R}$ is higher than for the rest of the food items.

Table 4. Annual effective dose $\left(\mu \mathbf{S v} \mathbf{y r}^{-1}\right)$ of ${ }^{228} \mathrm{R},{ }^{226} \mathrm{R}$, and ${ }^{40} \mathrm{~K}$ for samples in this study, compared to values determined for another foodstuff

\begin{tabular}{|l|c|c|c|c|c|}
\hline Foodstuff & ${ }^{\mathbf{2 2 8}} \mathbf{R}$ & ${ }^{{ }^{226} \mathbf{R}}$ & ${ }^{\mathbf{4 0}} \mathbf{K}$ & Total & Reference \\
\hline Egg & 17.5 & 25.2 & 36.3 & 79 & (Present study) \\
\hline Cereal & 16.7 & 29.4 & 83.2 & 129 & (Alrefae, 2013) \\
\hline Seafood & - & 3 & 2 & 5 & (Alrefae, 2014) \\
\hline Milk (Adult) & 2 & 2 & 43 & 47 & (Alrefae, 2012) \\
\hline Palm dates & 4 & 4 & 24 & 32 & (Alrefae, 2015) \\
\hline Rice & & & 23 & 23 & (Alrefae, 2013) \\
\hline General & & & 170 & & (Unscear, 2000) \\
\hline
\end{tabular}

\section{Conclusion}

The presence of three naturally occurring radionuclides, namely ${ }^{228} \mathrm{Ra},{ }^{226} \mathrm{Ra}$, and ${ }^{40} \mathrm{~K}$, in the egg, was investigated using gamma spectroscopy. In agreement with similar studies, results revealed the presence of ${ }^{40} \mathrm{~K}$ in all samples, ${ }^{228} \mathrm{Ra}$ in most of the samples, and ${ }^{226} \mathrm{Ra}$ in only 6 samples out of the 25 investigated samples. Noteworthy, the activity concentrations of ${ }^{40} \mathrm{~K} \&{ }^{228} \mathrm{Ra}$ in the white egg were multiples of that of Yolk for one of the tested samples. In addition, the annual effective dose from egg consumption was calculated to be $79 \mu \mathrm{Sv} \mathrm{yr}^{-1}$, which is $1 / 4$ of the $290 \mu \mathrm{Sv} \mathrm{yr}^{-1}$ world average of the ingestion exposure from natural sources. Hence, no radiological hazards exist from egg consumption due to the presence of the investigated radionuclides.

The importance of this study emanates from the need to have a baseline of radioactivity exposure to the general public from ingestion of foodstuff. To have a more inclusive baseline, more types of foods need to be investigated, besides targeting alpha and beta-emitting radionuclides.

\section{ACKNOWLEDGMENTS}

The author thanks Mr. Tiruvachi Natrajan Nageswaran for his help in gamma spectrometry measurements and Mr. Taher Alshemali from the Center for Research in Environmental Radiation, Faculty of Science, Kuwait University, Shadadiyah, Kuwait. 


\section{References}

Alrefae, T., 2012. Radioactivity of long-lived gamma emitters in milk powder consumed in Kuwait and estimates of annual effective doses. Kuwait J. Sci. Eng., Volume 39(1A), pp. 143-158.

Alrefae, T., 2013. Nageswaran, T.N. and Al-Shemali, T., 2012. Radioactivity of long-lived gamma emitters in breakfast cereal consumed in Kuwait and estimates of annual effective doses. International Journal of Radiation Research, Volume 10(3), pp. 117-122.

Alrefae, T., 2013. Radioactivity of long-lived gamma emitters in rice consumed in Kuwait. Journal of the association of Arab universities for basic and applied sciences, Volume 13(1), pp. 24-27.

Alrefae, T., 2014. Radioactivity of long-lived gamma emitters in canned seafood consumed in Kuwait. Journal of the Association of Arab Universities for Basic and Applied Sciences, Volume 15, p. 6-9.

Alrefae, T., 2015. Long-lived gamma-emitting radionuclides in palm dates and estimates of annual effective doses. Health Physics, Volume 108(5), pp. 547-550.

Beresford, N.A., Fesenko, S., Konoplev, A., Skuterud, L., Smith, J.T. and Voigt, G., 2016. Thirty years after the Chernobyl accident: What lessons have we learned? Journal of environmental radioactivity, 157, pp.77-89.

Currie, L.A., 1968. Limits for qualitative detection and quantitative determination. Application to radiochemistry. Analytical Chemistry, 40(3), pp.586-593.

Faahnhof, A., 2003. Analysis of food by nuclear and related analytical techniques (No. NAHRES$-75)$.

Fry, R.J. and Fry, S.A., 1990. Health effects of ionizing radiation. The Medical Clinics of North America, 74(2), pp.475-488.

Hosseini, T., FATHI, V.A., Barati, H. and Karimi, M., 2006. Assessment of radionuclides in imported foodstuffs in Iran.

IAEA, I., 1989. Measurement of Radionuclides in Food and the Environment. International Atomic Energy Agency, Technical Report Series, No. 295.

ICRP, 1996. ICRP Publication 72: Age-dependent Doses to the Public Members from Intake of Radionuclides Part 5, Compilation of Ingestion and Inhalation Coefficients. Elsevier Health Sciences.

Ishikawa, T., 2017. Radiation doses and associated risk from the Fukushima nuclear accident: a review of recent publications. Asia Pacific Journal of Public Health, 29(2_suppl), pp.18S-28S.

Knoll, G.F., 2000. Radiation detection and measurement JOHN WILEY \& SONS. Inc., New York, p.65.

Olomo, J.B., 1990. The natural radioactivity in some Nigerian foodstuffs. Nuclear Instruments and Methods in Physics Research Section A: Accelerators, Spectrometers, Detectors, and Associated Equipment, 299(1-3), pp.666-669. 
Ortiz, P., Wheatley, J., Oresegun, M. and Friedrich, V., 1999. Lost and found dangers. Orphan radiation sources raise global concerns. IAEA Bulletin, 41(3), pp.18-21.

Osvath, I., Tarjan, S., Pitois, A., Groening, M. and Osborn, D., 2016. IAEA's ALMERA network: supporting the quality of environmental radioactivity measurements. Applied Radiation and Isotopes, 109, pp.90-95.

Shanthi, G., Maniyan, C.G., Raj, G.A.G. and Kumaran, J.T.T., 2009. Radioactivity in food crops from high-background radiation areas in southwest India. Current science, pp.1331-1335.

Unscear, S., 2000. effects of Ionizing Radiation. United Nations, New York, pp.453-487.

Yu, K.N. and Mao, S.Y., 1999. Assessment of radionuclide contents in food in Hong Kong. Health physics, 77(6), pp.686-696.

Submitted: $\quad 11 / 01 / 2021$

Revised: $\quad 25 / 03 / 2021$

Accepted: $\quad 15 / 08 / 2021$

DOI: $\quad 10.48129 /$ kjs. 11911 